\title{
Endovascular Coil Embolization of Distal Anterior Cerebral Artery Aneurysms: Angiographic and Clinical Follow-up Results
}

\author{
Hyun Seok Park, MD', Soon Chan Kwon, MD', Min-ho Kim, MD², Eun Suk Park, MD', \\ Hong Bo Sim, MD', In Uk Lyo, MD'
}

Purpose: This study is an overview of the clinical and angiographic outcomes of patients who undergo treatment for distal anterior cerebral artery aneurysms.

Materials and Methods: Between January 2009 and March 2012, 444 cerebral aneurysms were treated using endovascular coil embolization at our institute. Among them, 217 aneurysms were followedup with angiography at least six months later. Of these, there were 16 distal anterior cerebral artery (ACA) aneurysms in 16 patients. We conducted a retrospective review of clinical and radiological follow-up results of all patients with distal ACA aneurysms. The clinical and angiographic outcomes were assessed using the modified Rankin scale (mRS) and the Raymond classification scale, respectively.

Results: The mean age was $54.7 \pm 10.2$ years ( $41-75$ years). The mean follow-up period was $20.6 \pm 9.64$ months (6-37 months). Three patients presented with acute rupture. The average aneurysm size was $4.98 \pm 1.39 \mathrm{~mm}(3.0-8.1 \mathrm{~mm})$, and eight of 16 aneurysms $(50 \%)$ had aspect ratios $<2.0$. All 16 patients presented with complete obliteration immediately after the procedure. However, two patients had procedure-related complications, one with coil extrusion to the subarachnoid space without hemorrhage and one with thromboembolism subsequent to chemical thrombolysis. In the follow-up angiography, one major and five minor recurrences (for a total of six recurrences, 37.5\%) were detected. However, the differences between the ACA aneurysm group and others were not statistically significant. Clinical outcomes were good for all of the patients at the time of discharge (mean mRS: $0.25,0$ to 1 ) and at the follow-ups (mean mRS: 0 ).

Conclusion: Despite a comparatively high recurrence rate, the endovascular treatment of distal anterior cerebral aneurysms is feasible and has a good clinical outcome.

Key Words : Distal anterior cerebral artery; Aneurysm; Endovascular coil embolization; Recurrence

${ }^{1}$ Department of Neurosurgery and ${ }^{2}$ Biomedical Research Center, Ulsan University Hospital, University of Ulsan College of Medicine, Ulsan, Korea

Received June 14, 2013; accepted after revision July 29, 2013.

Correspondence to: Soon Chan Kwon, MD, PhD, Department of Neurosurgery, Ulsan University Hospital, University of Ulsan College of Medicine, 290-3 Jeonha-dong, Dong-gu, Ulsan 682-714, Korea.

Tel. 82.52.250.7139 Fax.82.52.250.7138 E-mail: nskwon.sc@gmail.com

This is an Open Access article distributed under the terms of the Creative Commons Attribution Non-Commercial License (http://creativecommons.org/licenses/by-nc/3.0) which permits unrestricted non-commercial use, distribution, and reproduction in any medium, provided the original work is properly cited. 
The surgical clipping of distal anterior cerebral artery (ACA) aneurysms using an interhemispheric approach poses several problems to the surgeon, such as operative space narrowing and sacrifice of the bridging vein. As a result, surgical morbidity has been reported to be relatively high $[1,2]$. Although endovascular treatment for ruptured or unruptured aneurysms has been increasingly used as a primary treatment option for intracranial aneurysms after the International Subarachnoid Aneurysmal Trial, endovascular treatment for distal ACA aneurysms is still challenging, similar to clipping results [3]. The endovascular treatment of distal ACA aneurysms was reported to be technically unsuccessful in some cases because of the distal location and small size of parent artery. The present paper reports our experience treating 16 distal ACA aneurysms using endovascular coiling.

\section{MATERIALS AND METHODS}

\section{Patient Demographics}

Between January 2009 and March 2012, 444 cerebral aneurysms were treated using endovascular coil embolization at our institute. Among them, 217 unruptured and ruptured aneurysms were follow-up with angiography at least six months later. Of these, there were 16 distal ACA aneurysms in 16 patients.

We performed a retrospective review of angiographic studies, including the medical records of patients who underwent coil embolization for cerebral aneurysms at our institute. The research protocol was approved by our Institutional Review Board.

\section{Procedure}

Endovascular treatment was performed under general anesthesia. Using preoperative intracranial angiography, the morphology and characteristics of the connections between the aneurysms and parent arteries were fully evaluated. The techniques used for coil embolization were similar to those described previously $[15,18]$. Aneurysms were embolized with detachable coils by packing as densely as possible. The embolization was stopped when angiographically complete obliteration was achieved, the last coil could not be introduced inside the sac, or the occlusion of the normal branch next to the aneurysm might occur. The percentage of occlusion at the end of the procedure was evaluated by determining the embolized volume using AngioCalc (http://www.angiocalc.com), with measurements from both three-dimensional and two-dimensional images. When the single-catheter technique was ineffective, a double-catheter or balloon- or stent-assisted technique was tried. Immediate angiographic results were classified according to the Raymond classification; complete occlusion, residual neck, and residual aneurysm [6]. Each patient's outcome was evaluated at discharge according to modified Rankin scale (mRS) [7].

\section{Angiographic and Clinical Follow-up}

Follow-up angiograms were performed at least six months after coil embolization, and the angiographic results were classified into three categories: stable or improved occlusion, minor recurrence that did not require retreatment, or major recurrence that required retreatment. Major recanalization was defined as contrast filling within the aneurysm dome or significant coil compaction for which the corresponding physician considered retreatment. Minor recanalization was defined as minimal coil compaction at the aneurysmal neck.

Clinical evaluations were performed in our outpatient clinic which is attended by one neurosurgeon.

\section{Statistical Analysis}

All of data were analysed using Statistical Package for Social Sciences (SPSS version, 19.0, SPSS Inc., Chicago, IL, USA). Fisher's exact test was used to recanalization rate. Significance level was set as 0.05.

\section{RESULTS}

\section{Patients and Angiographic Characteristics}

Sixteen patients with distal ACA aneurysms that were treated with endovascular coiling were reviewed in our study. The characteristics of the patients, clinical outcomes, and angiographic follow-up results are summarized in Table 1.

The mean age of the patients in our study was 54.7 \pm 10.2 years (range, $41-75$ years), and seven patients $(46.6 \%)$ were male. The mean follow-up period was $20.6 \pm 9.64$ months. Six patients were diagnosed with at least one other intracranial aneurysm, but no patient had another ACA aneurysm. Four patients (25\%) who presented with ruptured distal ACA aneurysm were treated emergently with no delay. The average longest diameter of aneurysm size was $4.98 \pm 1.39 \mathrm{~mm}(3.0-$ $8.1 \mathrm{~mm})$, and eight aneurysms (50\%) had an aspect ratio $<2.0$. The average longest diameter of aneurysm size in ruptured patients was $5.97 \mathrm{~mm}$, and three aneurysms $(75 \%)$ had an aspect ratio $<2.0$. In two cases, double-catheter technique was used for effective coil embolization. Immediate post-embolization control 


\section{Coil Embolization of Distal Anterior Cerebral Artery Aneurysms}

angiograms revealed complete occlusion in all of the patients.

\section{Procedure Complications}

Two patients had procedure-related complications. One patient had a coil extrusion that occurred intraoperatively without hemorrhage, indicated by a postoperative computed tomography (CT) scan. One patient received chemical thrombolysis (tirofiban, $0.5 \mathrm{mg}$ ) during coiling because of thromboembolism formation. A final angiogram revealed near resolution of the thromboembolism with complete occlusion of the aneurysm sac (TICI grade 3) [8]. Immediate pre- and post-procedural neurological changes were not checked. No remarkable findings suggested infarction with follow-up CT and magnetic resonance imaging.

\section{Follow-up Angiographic Findings and Clinical Outcomes}

Angiographic follow-up was performed at least 6 months later and was involved conventional angiography with DSA. All angiographic follow-up were evaluated and classified by an independent neuroradiologist. Recanalizations were noted in six aneurysms $(37.5 \%)$ in patients. One major and five minor recurrences were detected. The major recanalized aneurysm presented a stable result at the follow-up angiography 30 months after coil embolization, so additional treatment was not performed. There was no procedure-related major stroke or deaths. The last clinical follow-up outcome was good in all 16 patients (mean mRS: $0.25[0-1]$ ).

\section{DISCUSSION}

Distal ACA aneurysms are rare and comprise between $2 \%$ and $5.5 \%$ of intracranial aneurysms [9]. Ruptured or unruptured distal ACA aneurysms have been regarded as technically difficult to microsurgically clip because of the narrow operating field, interhemispheric

Table 1. Patient Characteristics

\begin{tabular}{|c|c|c|c|c|c|c|c|c|c|c|}
\hline No. & $\begin{array}{l}\text { Sex/ } \\
\text { Age }\end{array}$ & $\begin{array}{l}\text { Fisher } \\
\text { grade }\end{array}$ & $\begin{array}{l}\mathrm{H}-\mathrm{H} \\
\text { grade }\end{array}$ & $\begin{array}{l}\text { Size } \\
(\mathrm{mm})\end{array}$ & $\begin{array}{l}\text { Initial occlusion } \\
\text { rate (occlusion } \\
\text { volume, \%) }\end{array}$ & $\begin{array}{c}\text { Time for } \\
\text { last clinical } \\
\text { F/U }\end{array}$ & $\begin{array}{c}\text { Time for } \\
\text { F/U } \\
\text { angiography }\end{array}$ & $\begin{array}{l}\text { Occlusion } \\
\text { at } \\
\text { follow-up }\end{array}$ & $\mathrm{mRS}$ & Remarks \\
\hline 1 & $F / 65$ & 1 & 0 & $4.2 \times 3.6$ & 26.74 & 14 months & 6 months & SO & 0 & \\
\hline 2 & $\mathrm{M} / 41$ & 3 & 3 & $7.8 \times 7.5$ & 22.12 & 7 months & 6 months & SO & 0 & Multiple catheter \\
\hline 3 & $\mathrm{~F} / 51$ & 3 & 3 & $5.2 \times 3.2$ & 21.74 & 9 months & 6 months & Min R & 1 & Multiple catheter \\
\hline 4 & $\mathrm{~F} / 75$ & 1 & 0 & $4.8 \times 4.5$ & 29.23 & 38 months & 10 months & Min R & 0 & \\
\hline 5 & $\mathrm{M} / 56$ & 1 & 0 & $3.0 \times 2.5$ & 17.23 & 8 months & 7 months & Min R & 0 & \\
\hline 6 & $F / 46$ & 1 & 0 & $3.7 \times 3.5$ & 13.16 & 25 months & 6 months & SO & 0 & \\
\hline 7 & $\mathrm{M} / 57$ & 1 & 0 & $5.1 \times 3.1$ & 34.47 & 39 months & 6 months & Min R & 0 & \\
\hline 8 & $F / 61$ & 1 & 0 & $4.1 \times 2.1$ & 21.34 & 37 months & 37 months & SO & 0 & $\begin{array}{l}\text { Protrusion to parent } \\
\text { artery; asymptomatic }\end{array}$ \\
\hline 9 & $\mathrm{M} / 41$ & 2 & 3 & $5.7 \times 3.6$ & 11.83 & 15 months & 30 months & Maj R & 1 & \\
\hline 10 & $\mathrm{~F} / 47$ & 1 & 0 & $4.6 \times 2.6$ & 12.74 & 39 months & 6 months & SO & 0 & \\
\hline 11 & $\mathrm{M} / 54$ & 1 & 0 & $8.1 \times 3.6$ & 36.88 & 7 months & 7 months & SO & 0 & \\
\hline 12 & $\mathrm{M} / 59$ & 1 & 0 & $5.6 \times 3.4$ & 20.68 & 37 months & 6 months & SO & 1 & $\begin{array}{c}\text { Thromboembolism; } \\
\text { asymptomatic }\end{array}$ \\
\hline 13 & $\mathrm{M} / 54$ & 1 & 0 & $3.4 \times 2.0$ & 15.31 & 19 months & 19 months & SO & 0 & \\
\hline 14 & $\mathrm{~F} / 50$ & 1 & 0 & $4.2 \times 1.6$ & 17.47 & 19 months & 18 months & Min R & 0 & \\
\hline 15 & $\mathrm{~F} / 73$ & 2 & 2 & $5.2 \times 3.1$ & 17.57 & 8 months & 6 months & SO & 1 & \\
\hline 16 & $\mathrm{~F} / 45$ & 1 & 0 & $4.9 \times 3.1$ & 19.71 & 8 months & 7 months & SO & 0 & \\
\hline
\end{tabular}

Abbreviations: $\mathrm{H}-\mathrm{H}$ grade, Hunt and Hess grade; F/u, follow-up, SO, stable occlusion; Maj R, major recanalization; Min R, minor recanalization 
Hyun Seok Park, et al.

Table 2. Rate of Endovascular Treatment using Tool Assistance

\begin{tabular}{lccccr}
\hline Aneurysm location & Stent-assisted & Balloon-assisted & Double-catheters & Combined technique & Total \\
\hline All (Except distal ACA) & 18 & 35 & 77 & 3 & $133 / 201(66.2 \%)$ \\
Distal ACA & 0 & 0 & 2 & 0 & $2 / 16(13.3 \%)$ \\
\hline
\end{tabular}

Abbreviation: ACA, anterior cerebral artery

Table 3. Case Series of Recurrence after Coil Embolization

\begin{tabular}{lcccc}
\hline Series & Total cases & Aneurysm location & Time for follow-up (months) & Recurrence case \\
\hline Raymond J et al. [6] & 297 & All & 12.31 & $98(32 \%)$ \\
\hline Gonzalez N et al. [16] & 79 & A-com & 6.7 & $12(15 \%)$ \\
Jin SC et al. [17] & 55 & ICA & 29.7 & $16(29.1 \%)$ \\
Kim BM et al. [18] & 69 & MCA & 12 & $9(13 \%)$ \\
Tan IY et al. [19] & 98 & All & 6.2 & $15(15.3 \%)$ \\
\hline Present study & 201 & All except distal ACA & 8.05 & $52(25.9 \%)$ \\
\hline
\end{tabular}

Abbreviations: MCA, Middle cerebral artery; A-com, Anterior communicating artery; ICA, Internal carotid artery; ACA, Anterior cerebral artery.

Table 4. Mean Percentage of Occlusion Volume (\%) and Recurrence Rate (\%)

\begin{tabular}{lccc}
\hline Series & Cases & Occlusion volume (\%) & Recurrence rate (\%) \\
\hline Suzuki et al. [2] & 144 & 27.3 & 27 \\
\hline Piotin et al. [20] & 255 & 30.4 & 28.6 \\
Vallée et al. [21] & 160 & 24.7 & 28 \\
Yagi et al. [22] & 100 & 21.1 & 3 \\
\hline Present study & 16 & & 28 \\
\hline
\end{tabular}

adhesions, especially with ruptured aneurysms, difficulty preserving the parent artery, and an unfavorable direction of the clipping fundus. Endovascular coil embolization has been widely used as an alternative to microsurgical clipping and considered a first-choice modality for the treatment of ruptured or unruptured intracranial aneurysms [10-12]. Distal ACA aneurysm is also one indication for endovascular treatment. However, despite the evolution of techniques and tools, the coiling of distal ACA aneurysms is complicated. For the endovascular treatment of distal ACA aneurysms, the use of multiple devices, such as double catheters, balloons, or stents is limited compared with other aneurysms located elsewhere. For distal ACA aneurysms, the rate of tool assistance was lower than for aneurysms located elsewhere ( $p$-value $<0.001$; Table 2 ). This difference can be explained by the fact of relatively small caliber of parent artery (A2) and distally located lesion. However, if the procedure is performed carefully and with the proper indications, then the procedure can be accomplished successfully without complications, such as thrombosis or microcatheter protrusion or extrusion. There were two procedure-related complications during coil embolization of ACA aneurysms, one was coil protrusion and the other was thromboembolic complication. Thromboembolic complication occurred in one of 16 patients $(6.3 \%)$ in our study. This rate is similar to the rates of $0-17.2 \%$ reported in previous studies [9, 13-15].

We performed angiographic follow-up at least six months after embolization in all of the cases in the present study. Of the 16 aneurysms, there was one major recanalization, and five minor recanalized recurrences, owing to regrowth of the aneurysm and coil compaction. The recanalization rate was high compared with the follow-up angiographic results of 


\section{Coil Embolization of Distal Anterior Cerebral Artery Aneurysms}

studies of aneurysms at other locations (Table 3 ) [6, 16-19]. Therefore, surgeons should be aware of the high possibility of recurrence during endovascular procedures.

In the present study, the loose coil packing rate may have been a significant predictor of recurrence. Compared with several studies, the packing rate of distal ACA aneurysms was lower (Table 4) [2, 20-22]. Our clinical outcomes were very encouraging. All of the patients had an mRS score of 0 to 1 at the last recorded follow-up. This indicates that endovascular treatment may be an option for distal ACA aneurysms.

The present study had a few limitations. Although some angiographic data were researched prospectively, most of the data in the study were reviewed retrospectively. In the chart review, endovascularly treated distal ACA aneurysms without angiographic follow-up were excluded. Therefore, recanalization cases that did not undergo angiographic follow-up were not contained in the analysis. Additionally, more patients with longer follow-up times are needed.

In conclusion, the endovascular treatment of distal ACA aneurysms is feasible and has a good clinical outcome. However, the recurrence rate of coiled aneurysms is higher compared with aneurysms at other locations. When surgeons select the treatment modality for distal ACA aneurysms, they should be aware of the high rate of recurrence after endovascular treatment.

\section{References}

1. Cavalcanti DD, Abla AA, Martirosyan NL, McDougall CG, Spetzler RF, Albuquerque FC. Endovascular management of distal ACA aneurysms: single-institution clinical experience in 22 consecutive patients and literature review. AJNR Am J Neuroradiol 2013 Feb 7. [Epub ahead of print].

2. Suzuki S, Kurata A, Yamada M, Iwamoto K, Nakahara K, Sato K, et al. Outcomes analysis of ruptured distal anterior cerebral artery aneurysms treated by endosaccular embolization and surgical clipping. Interv Neuroradiol 2011;17:49-57

3. Molyneux A, Kerr R, Stratton I, Sandercock P, Clarke M, Shrimpton J, et al. International Subarachnoid Aneurysm Trial(ISAT) of neurosurgical clipping versus endovascular coiling in 2143 patients with ruptured intracranial aneurysms: a randomized trial. J Stroke Cerebrovasc Dis 2002;11:304-314

4. Roy D, Milot G, Raymond J. Endovascular treatment of unruptured aneurysms. Stroke 2001;32:1998-2004

5. Vallé e JN, Pierot L, Bonafé A, Turjman F, Flandroy P, Berge J, et al. Endovascular treatment of intracranial wide-necked aneurysms using three-dimensional coils: predictors of immediate anatomic and clinical results. AJNR Am J Neuroradiol 2004;25:298-306

6. Raymond J, Guilbert F, Weill A, Georganos SA, Juravsky L, Lambert A, et al. Long-term angiographic recurrences after selective endovascular treatment of aneurysms with detachable coils. Stroke 2003;34:1398-1403

7. Rankin J. Cerebral vascular accidents in patients over the age of 60. II. Prognosis. Scott Med J 1957;2:200-215

8. Macleod MR, Davis SM, Mitchell PJ, Gerraty RP, Fitt G, Hankey GJ, et al. Results of a multicentre, randomised controlled trial of intra-arterial urokinase in the treatment of acute posterior circulation ischaemic stroke. Cerebrovasc Dis 2005;20:12-17

9. Menovsky T, van Rooij WJ, Sluzewski M, WijnaldaD. Coiling of ruptured pericallosal artery aneurysms. Neurosurgery 2002;50: $11-14$

10. Kim BM, Park SI, Kim DJ, Kim DI, Suh SH, Kwon TH, et al. Endovascular coil embolization of the auerysms with a branch incorporated into the sac. AJNR Am J Neuroradiol 2010;31:145151

11. Raymond J, Roy D. Safety and efficacy of endovascular treatment of acutely ruptured aneurysms. Neurosurgery 1997;41:1235-1245

12. Regli L, Uske A, de TriboletN. Endovascular coil placement compared with surgical clipping for the treatment of unruptured middle cerebral artery aneurysms: a consecutive series. $J$ Neurosurg 1999;90:1025-1030

13. Nguyen TN, Raymond J, Roy D, Chagnon M, Weill A, IancuGontard D, et al. Endovascular treatment of pericallosal aneurysms. J Neurosurg 2007;107:973-976

14. Vora N, Thomas AJ, Gupta R, Gologorsky Y, Panapitiya N, Jovin $\mathrm{T}$, et al. Endovascular treatment of distal anterior cerebral artery aneurysms: technical results and review of the literature. $J$ Neuroimaging 2010;20:70-73

15. Waldenberger P, Petersen J, Chemelli A, Schenk C, Gruber I, Strasak A, et al. Endovascular therapy of distal anterior cerebral artery aneurysms-an effective treatment option. Surg Neurol 2008;70:368-377

16. Gonzalez N, Sedrak M, Martin N, VinuelaF. Impact of anatomic features in the endovascular embolization of 181 anterior communicating artery aneurysms. Stroke 2008;39:2776-2782

17. Jin SC, Kwon do H, Ahn JS, Kwun BD, Song Y, Choi CG. Clinical and radiogical outcomes of endovascular detachable coil embolization in paraclinoid aneurysms : a 10-year experience. $J$ Korean Neurosurg Soc 2009;45:5-10

18. Kim BM, Kim DI, Park SI, Kim DJ, Suh SH, Won YS. Coil embolization of unruptured middle cerebral artery aneurysms. Neurosurgery 2011;68:346-353

19. Tan IY, Agid RF, Willinsky RA. Recanalization rates after endovascular coil embolization in a cohort of matched ruptured and unruptured cerebral aneurysms. Interv Neuroradiol 2011;17: 27-35

20. Piotin M, Spelle L, Mounayer C, Salles-Rezende MT, GiansanteAbud D, Vanzin-Santos R, et al. intracranial aneurysms: treatment with bare platinum coils--aneurysm packing, complex coils, and angiographic recurrence. Radiology 2007;243:500-508

21. Vallée JN, Pierot L, Mont'alverne F, Turjman F, Bonafé A, Bracard S, et al. Unruptured intracranial aneurysms treated by three-dimensional coil embolization: evaluation of the postoperative aneurysm occlusion volume. Neuroradiology 2005;47:438445

22. Yagi K, Satoh K, Satomi J, Matsubara S, Nagahiro S. Evaluation of aneurysm stability after endovascular embolization with Guglielmi detachable coils: correlation between long-term stability and volume embolization ratio. Neurol Med Chir (Tokyo) 2005;45:561-565 